\title{
Application of Remifentanil in Analgesia and Sedation of Mechanically Ventilated Patients in Intensive Care Unit
}

\author{
Y. H. WANG ${ }^{1}$ AND XIUMING $X^{*}$
}

Department of Critical Care Medicine, Fuxing Hospital, Capital Medical University, Beijing 100038, ${ }^{1}$ Department of Critical Care Medicine, North China University of Science and Technology Affiliated Hospital, Tangshan 063000, China

\section{Wang et al.: Application of Remifentanil in Analgesia and Sedation}

To observe the analgesic and sedative effect of remifentanil in patients with mechanical ventilation in intensive care unit and to explore the application value of remifentanil in intensive care unit patients with mechanical ventilation. 164 patients were randomly divided into remifentanil combined with dexmedetomidine group (R group), sufentanil combined with dexmedetomidine group (S group) where 82 patients in each group. The patients in the two groups were assessed with the pain observation instrument of intensive care (critical care pain observation tool) for analgesia score and the sedative effect was assessed with the Ramsay scale. The vital signs during the treatment, the time for patients to achieve satisfactory analgesia and sedation, the time for mechanical ventilation, the time for intensive care unit hospitalization and the occurrence of adverse reactions were recorded respectively. Both groups of patients can achieve satisfactory analgesic and sedative effect. Critical care pain observation tool score of patients in the two groups was significantly lower than that before treatment $(p<0.05)$, the percentage of Ramsay assessment grade 3-4 of patients in the $\mathrm{R}$ group was significantly higher than that in the $\mathrm{S}$ group. Heart rate, map of mean arterial pressure and autonomic respiratory rate of patients in the two groups were significantly lower than that before treatment $(\mathrm{p}<\mathbf{0 . 0 5})$. There was no significant difference in heart rate between the two groups $(\mathbf{p}>\mathbf{0 . 0 5})$, map of mean arterial pressure of patients in the $R$ group was significantly higher than that in the $S$ group immediately after treatment $(p<0.05)$; respiratory rate in $R$ group was significantly lower than that in $\mathrm{S}$ group $(\mathbf{p}<\mathbf{0 . 0 5})$. The time of analgesia and sedation $(\mathrm{min})$, mechanical ventilation $(H)$ and intensive care unit hospitalization $(H)$ in group $R$ were significantly shorter than that in group $S$ $(p<0.05)$. The number of hypotension patients in $R$ group was more than that in $S$ group and delirium and agitation were lower than those in $\mathrm{S}$ group $(\mathbf{p}<\mathbf{0 . 0 5})$. Remifentanil combined with dexmedetomidine can rapidly achieve the goal of analgesia and sedation, improve vital signs and shorten the time of satisfactory analgesia and sedation, mechanical ventilation, hospital stay and no serious adverse reactions.

Key words: Remifentanil, mechanical ventilation, sedation, analgesia

Intensive care unit (ICU) patients are those with mechanical ventilation in the disease itself and the various factors in the hospital environment, patients in the intense stress environment vulnerable to endotracheal intubation and mechanical ventilation treatment of stimulation, pain, anxiety, restlessness and other physiological and psychological reactions ${ }^{[1]}$ under the influence of many factors such as pain, anxiety and delirium undesirable phenomena, causing a series of pathophysiological changes, even life safety, threat patients ${ }^{[2]}$ and proper analgesic calm strategy is an effective measure to reduce the psychological and physiological adverse experience ${ }^{[3]}$. Sufentanil and remifentanil are synthetic phenylpiperidine drugs, which are the most commonly used drugs in clinical anesthesia and analgesia. Pharmacologic functions such as analgesia and sedation are performed by activating opioid receptors in the body. In this study, the remifentanil combined with dexmedetomidine treatment group ( $\mathrm{R}$ group) and the sufentanil combined with dexmedetomidine treatment group ( $\mathrm{S}$ group) were selected to observe and compare the effects of different

*Address for correspondence

E-mail: w64237568@163.com 
analgesics on the treatment, so as to explore the best treatment scheme for critical patients with mechanical ventilation.

\section{MATERIALS AND METHODS}

\section{General information:}

A total of 164 patients with mechanical ventilation in ICU admitted to our hospital from March 2019 to December 2019 were selected, including 81 males and 83 females of age: 18 65 y old, average age: $48.25 \pm 9.76$ y old, weight: $50 \sim 81 \mathrm{~kg}$, average weight: $61.22 \pm 5.83 \mathrm{~kg}$ were randomly divided into remifentanil combined with dexmedetomidine treatment group ( $\mathrm{R}$ group) and sufentanil combined with dexmedetomidine treatment group ( $\mathrm{S}$ group). There were 82 patients in each group. There was no statistically significant difference in gender, age, weight and other general information between the two groups $(\mathrm{p}>0.05)$, indicating comparability (Table 1).

\section{TABLE 1: COMPARISON OF TEST RESULTS IN EACH GROUP}

\begin{tabular}{lcc}
\hline Project & R group $(n=82)$ & S group $(n=82)$ \\
\hline Weight $(x \pm s, k g)$ & $59.8 \pm 5.6$ & $60.9 \pm 5.1$ \\
Age $(x \pm s)$ & $47.6 \pm 9.9$ & $50.0 \pm 7.1$ \\
Gender $(n)$ & & \\
Men & 40 & 41 \\
Women & 42 & 41 \\
APACHE II score & $13.6 \pm 6.1$ & $2.6 \pm 7.3$ \\
$(x \pm s$, points) & &
\end{tabular}

\section{Inclusion and exclusion criteria:}

Inclusion criteria-Patients in the respiratory failure state; increased partial pressure of carbon dioxide; hemodynamic stability, no vasoactive drugs were used; the acute physiology and chronic health evaluation II (APACHE II) score of all patients in the group were more than 10 points; the informed consent was signed and the study was approved by the hospital ethics committee.

Exclusion criteria-Those who do not meet the diagnostic criteria for respiratory failure; patients with severe hemodynamic instability or severe hepatic and renal insufficiency; the duration of analgesia and sedation is less than $48 \mathrm{~h}$ and continuous blood purification treatment is given during the treatment; atrioventricular block; coma; patients with acute delayed paralysis or receiving muscle relaxant; persons suffering from mental illness; patients with consciousness disorder; patients with craniocerebral injury; allergic or contraindicated to remifentanil, sufentanil, dexmedetomidine; pregnant and lactating women.

\section{Treatment:}

Both groups of patients were active in primary and symptomatic treatment and follow the analgesic sedation treatment program. $\mathrm{R}$ group: remifentanil injection (specification: $2 \mathrm{mg} /$ dose; After $1 \mathrm{~h}$ of load, use the micro injection pump $0.05 \mathrm{~h} /(\mathrm{kg} /$ $\mathrm{min}$ ) continuous intravenous infusion, every $5 \mathrm{~min}$ interval using the ICU pain observation tool method (critical care pain observation tool (CPOT)) to assess the analgesic effect, with $\mathrm{CPOT}<2$ as the target. If $\mathrm{CPOT} \geq 2 \mathrm{~min}$, the dynamic adjustment of remifentanil dosage at the speed of $0.5 \mathrm{~g} /(\mathrm{kg} / \mathrm{h})$. Use in group S: sufentanil citrate injection (specification: $2 \mathrm{ml}: 100 \mathrm{~g}$; Yichang Renfu Pharmaceutical co., Ltd.), after $0.2 \mathrm{~kg}$ of load, the micro injection pump was used to provide $0.01 \mathrm{~g} /(\mathrm{kg} / \mathrm{h})$ continuous intravenous infusion and the infusion speed of sufentanil was adjusted every 5 min according to the clinical observation of patients reactions, until CPOT $<2$ min. All enrolled patients were given dexmedetomidine hydrochloride injection on the basis of analgesia (specification: $2 \mathrm{ml}: 200 \mathrm{~g}$; Jiangsu Hengrui pharmaceutical co., Ltd.) sedation treatment: $1 \mu \mathrm{g} / \mathrm{kg}$ intravenous infusion slowly with infusion time over $10 \mathrm{~min}$, use a micro injection pump $1 \mathrm{~g} /(\mathrm{kg} / \mathrm{h})$ continuous intravenous infusion with interval of $5 \mathrm{~min}$. Adjust the maintenance dose according to the standard Ramsay score of $3 \sim 4$ points, increasing or decreasing at $1 \mathrm{~g} / \mathrm{kg} / \mathrm{min}$ until the ideal condition. Heart rate (HR), respiratory rate (RR) and mean arterial pressure (MAP) were monitored with multifunctional monitors. Both groups used the same offline indications, including daily arousal, a Ramsay score of 3-4 and were able to extract tracheal tubes through $2 \mathrm{~h}$ independent breathing screening.

\section{Observation indicators:}

In this study, the patients were evaluated and the drug dosage was adjusted according to the evaluation results until the satisfactory analgesic and sedative effects were achieved. Analgesia score: pain observation tool (COPT) was used for severe patients. Analgesia target: COPT score $<3$. The 
sedation score was assessed by the Ramsay sedation scale $^{[4]}$. Level 2: patient cooperation, sober and quiet; level 3: the patient only responds to instructions; level 4: the patient falls asleep and responds quickly to eyebrow tapping; level 5: the patient fell asleep and had a slow response to eyebrow tapping; level 6: the patient is in a state of deep sleep or anesthesia. The ideal sedation depth for mechanically ventilated patients is grade 3-4. In the treatment process, the higher the percentage of Ramsay rating at level $3-4$, the better the sedative effect ${ }^{[5,6]}$. The incidence of delirium was recorded using the ICU fuzzy assessment of consciousness (confusion assessment method for the ICU (CAM-ICU)) and the occurrence of hypotension, delirium, bradycardia and other adverse reactions were observed and recorded. All patients in the group were recorded for physiological indexes and at the same time observe and record the two groups of patients with drug use and satisfied sedation analgesia after 0 h, 4 h, 8 h, 16 h, 24 h CPOT grade, Ramsay, MAP, HR, spontaneous breathing frequency, satisfactory sedation analgesia time, mechanical ventilation, ICU length of hospital stay, adverse reactions, etc., and analyze the data.

\section{Statistical analysis:}

Statistical package for the social sciences (SPSS) 17.0 statistical software was used. The measurement data were represented by $(\overline{\mathrm{x}} \pm \mathrm{s})$. The analysis of variance (ANOVA) of two factor repeated measurement was used for inter group comparison and the ANOVA of single factor repeated measurement was used for intra group comparison. The enumeration data were expressed as $n$ or $\%$ and the $\chi^{2}$ test or Fisher test were used for comparison between groups. $\mathrm{p}<0.05$ was considered statistically significant.

\section{RESULTS AND DISCUSSION}

There was no statistically significant difference in CPOT score between the two groups before medication $(\mathrm{p}>0.05)$. After drug administration, the CPOT score of both groups decreased $(p<0.05)$ and the analgesia target was achieved. There was no statistically significant difference between the two groups at each time point ( $\mathrm{p}>0.05)$ (Table 2 ).
There was no statistically significant difference in Ramsay score between the two groups before medication $(\mathrm{p}>0.05)$. Through drug administration, both groups could achieve the goal of analgesia and there was no statistically significant difference between the two groups before, immediately after, $16 \mathrm{~h}$ and $24 \mathrm{~h}$ of medication ( $\mathrm{p}>0.05$ ). The difference between the two groups was statistically significant $(\mathrm{p}<0.05)$. Compared with group $\mathrm{S}$, the percentage of patients in group $\mathrm{R}$ with Ramsay assessment level 3-4 was significantly higher (Table 3).

The physiological indexes selected in this study were HR, MAP and RR before and after medication. HR, MAP and RR in the two groups were significantly reduced after medication compared with before medication, with statistically significant differences $(\mathrm{p}<0.05)$. There was no significant difference in HR between the two groups $(p>0.05)$ (Table 4). The immediate MAP in group R decreased significantly compared with group $\mathrm{S}$ and the difference was statistically significant $(\mathrm{p}<0.05)$. The MAP difference at other time points was not statistically significant ( $\mathrm{p}>0.05)$. The spontaneous breathing rate of $\mathrm{R}$ group at each time point was significantly lower than that of $\mathrm{S}$ group $(\mathrm{p}<0.05)$ (Table 5 and Table 6$)$.

Other hospitalization indexes selected in this study were satisfactory with analgesic and sedative time, mechanical ventilation and length of stay in ICU. Compared with group $\mathrm{S}$, group $\mathrm{R}$ patients achieved satisfactory analgesia and sedation time, average mechanical ventilation time and average ICU hospitalization time were shorter, the differences were statistically significant $(\mathrm{p}<0.05)$, as shown in Table 7.

In comparison with the occurrence of adverse reactions in the two groups, the number of cases of hypotension in group $\mathrm{R}$ was significantly higher than that in group $S(p<0.05)$. The number of cases of delirium in group $\mathrm{S}$ was higher than that in group $R$ (but $p>0.05$ ). The number of cases of restlessness in group $\mathrm{S}$ was higher than that in group $\mathrm{R}$ (but $\mathrm{p}>0.05$ ) as shown in Table 8. Muscle stiffness and hypersedation were not observed in either group. 
TABLE 2: COMPARISON OF COPT ANALGESIA SCORES BETWEEN THE TWO GROUPS AT DIFFERENT TIME PERIODS $(\overline{\mathbf{x}} \pm \mathbf{s})$

\begin{tabular}{lccccccc}
\hline Group & $\mathrm{N}$ & $\begin{array}{c}\text { Before } \\
\text { medication }\end{array}$ & Immediately & After $4 \mathrm{~h}$ & After $8 \mathrm{~h}$ & After $16 \mathrm{~h}$ & After $24 \mathrm{~h}$ \\
\hline R group & 82 & $4.2 \pm 2.2$ & $1.7 \pm 0.3^{*}$ & $1.6 \pm 0.6^{*}$ & $1.4 \pm 0.5^{*}$ & $1.3 \pm 0.6^{*}$ & $1.2 \pm 0.5^{*}$ \\
S group & 82 & $4.6 \pm 2.3$ & $1.8 \pm 0.5^{*}$ & $1.7 \pm 0.6^{*}$ & $1.5 \pm 0.4^{*}$ & $1.4 \pm 0.5^{*}$ & $1.3 \pm 0.4^{*}$ \\
$\mathrm{t}$ & & 0.47 & 0.60 & 0.42 & 0.65 & 0.51 & 0.61 \\
$\mathrm{P}$ & $>0.05$ & $>0.05$ & $>0.05$ & $>0.05$ & $>0.05$ & $>0.05$ \\
\hline
\end{tabular}

Note: Compared with the group before medication, ${ }^{*} \mathrm{p}<0.05$

TABLE 3: COMPARISON OF RAMSAY SEDATION SCORES BETWEEN THE TWO GROUPS AT DIFFERENT TIME PERIODS $(\overline{\mathbf{x}} \pm \mathbf{s})$

\begin{tabular}{lccccccc}
\hline Group & $\mathrm{N}$ & $\begin{array}{c}\text { Before } \\
\text { medication }\end{array}$ & Immediately & After $4 \mathrm{~h}$ & After $8 \mathrm{~h}$ & After 16 h & After $24 \mathrm{~h}$ \\
\hline R group & 82 & $4.2 \pm 2.2$ & $1.7 \pm 0.3^{*}$ & $1.6 \pm 0.6^{*}$ & $1.4 \pm 0.5^{*}$ & $1.3 \pm 0.6^{*}$ & $1.2 \pm 0.5^{*}$ \\
S group & 82 & $4.6 \pm 2.3$ & $1.8 \pm 0.5^{*}$ & $1.7 \pm 0.6^{*}$ & $1.5 \pm 0.4^{*}$ & $1.4 \pm 0.5^{*}$ & $1.3 \pm 0.4^{*}$ \\
t & & 0.47 & 0.60 & 0.42 & 0.65 & 0.51 & 0.61 \\
P & & $>0.05$ & $>0.05$ & $>0.05$ & $>0.05$ & $>0.05$ & $>0.05$ \\
\hline
\end{tabular}

TABLE 4: HR (BEATS/MIN) AT EACH MEDICATION TIME POINT OF THE TWO GROUPS

\begin{tabular}{|c|c|c|c|c|c|c|c|}
\hline Group & $\mathbf{N}$ & $\begin{array}{c}\text { Before } \\
\text { medication }\end{array}$ & Immediately & After $4 \mathrm{~h}$ & After $8 \mathrm{~h}$ & After $16 \mathrm{~h}$ & After $24 \mathrm{~h}$ \\
\hline $\mathrm{R}$ group & 82 & $109.5 \pm 29.7$ & $86.4 \pm 21.9^{*}$ & $85.2 \pm 28.2^{*}$ & $86.5 \pm 23.6^{*}$ & $90.5 \pm 8.9^{*}$ & $89.3 \pm 15.6^{*}$ \\
\hline S group & 82 & $111.3 \pm 31.0$ & $87.7 \pm 19.3^{*}$ & $89.4 \pm 9.2^{*}$ & $88.3 \pm 10.5^{*}$ & $86.5 \pm 15.3^{*}$ & $90.1 \pm 29.1^{*}$ \\
\hline $\mathrm{t}$ & & 0.16 & 0.18 & 0.52 & 0.30 & 0.83 & 0.11 \\
\hline$p$ & & $>0.05$ & $>0.05$ & $>0.05$ & $>0.05$ & $>0.05$ & $>0.05$ \\
\hline
\end{tabular}

Note: Compared with the group before medication, ${ }^{*} p<0.05$

TABLE 5: MAP AT EACH MEDICATION TIME POINT IN THE TWO GROUPS (mmHg)

\begin{tabular}{|c|c|c|c|c|c|c|c|}
\hline Group & $\mathbf{N}$ & $\begin{array}{c}\text { Before } \\
\text { medication }\end{array}$ & Immediately & After $4 \mathrm{~h}$ & After $8 \mathrm{~h}$ & After $16 \mathrm{~h}$ & After $24 \mathrm{~h}$ \\
\hline $\mathrm{R}$ group & 82 & $86.6 \pm 18.5$ & $69.6 \pm 5.9^{*}$ & $71.5 \pm 6.3^{*}$ & $70.5 \pm 7.0^{*}$ & $71.5 \pm 4.5^{*}$ & $74.3 \pm 6.6^{*}$ \\
\hline S group & 82 & $84.3 \pm 12.5$ & $76.4 \pm 8.1^{*}$ & $74.5 \pm 7.6^{*}$ & $75.2 \pm 6.5^{*}$ & $75.6 \pm 7.5^{*}$ & $77.1 \pm 7.3^{*}$ \\
\hline $\mathrm{t}$ & & 0.41 & 2.55 & 1.16 & 1.86 & 1.72 & 1.25 \\
\hline $\mathrm{p}$ & & $>0.05$ & $<0.05$ & $>0.05$ & $>0.05$ & $>0.05$ & $>0.05$ \\
\hline
\end{tabular}

Note: Compared with the group before medication, ${ }^{*} \mathrm{p}<0.05$ 
TABLE 6: SPONTANEOUS BREATHING RATE (TIMES/MIN) AT EACH MEDICATION TIME POINT IN THE TWO GROUPS

\begin{tabular}{lccccccc}
\hline Group & $\mathrm{N}$ & $\begin{array}{c}\text { Before } \\
\text { medication }\end{array}$ & Immediately & After $4 \mathrm{~h}$ & After $8 \mathrm{~h}$ & After $16 \mathrm{~h}$ & After $24 \mathrm{~h}$ \\
\hline R group & 82 & $14.5 \pm 4.1$ & $8.3 \pm 2.5^{*}$ & $7.7 \pm 3.1^{*}$ & $6.9 \pm 2.2^{*}$ & $7.0 \pm 2.8^{*}$ & $6.3 \pm 2.1^{*}$ \\
$\mathrm{~S}$ group & 82 & $15.3 \pm 3.7$ & $11.8 \pm 4.5^{*}$ & $10.6 \pm 3.6^{*}$ & $10.1 \pm 2.7^{*}$ & $10.6 \pm 2.9^{*}$ & $8.9 \pm 2.8^{*}$ \\
$\mathrm{t}$ & & 0.56 & 2.59 & 2.45 & 3.46 & 3.46 & 2.81 \\
$\mathrm{p}$ & $>0.05$ & $<0.05$ & $<0.05$ & $<0.05$ & $<0.05$ & $<0.05$ \\
\hline
\end{tabular}

Note: Compared with the group before medication, * $p<0.05$

TABLE 7: SATISFACTORY SEDATION AND ANALGESIA TIME, MECHANICAL VENTILATION TIME AND LENGTH OF STAY IN ICU

\begin{tabular}{lcccc}
\hline Group & $\mathrm{N}$ & Satisfactory sedation and analgesia $(\mathrm{min})$ & Mechanical ventilation $(\mathrm{H})$ & $\mathrm{ICU}(\mathrm{H})$ \\
\hline R group & 82 & $5.2 \pm 1.5$ & $73.5 \pm 26.7$ & $138.2 \pm 35.6$ \\
S group & 82 & $17.8 \pm 3.6$ & $94.9 \pm 37.3$ & $168.3 \pm 41.1$ \\
$\mathrm{t}$ & & 12.86 & 2.05 & 2.01 \\
$\mathrm{p}$ & $<0.05$ & $<0.05$ & $<0.05$ \\
\hline
\end{tabular}

TABLE 8: COMPARISON OF ADVERSE REACTIONS BETWEEN THE TWO GROUPS [n (\%)]

\begin{tabular}{llccc}
\hline Group & N & Low blood pressure & Delirium & Restlessness \\
\hline R group & 82 & $3(3.66)$ & $3(3.66)$ & $1(1.22)$ \\
S group & 82 & $1(1.22)$ & $5(6.10)$ & $5(6.10)$ \\
\hline
\end{tabular}

Analgesics and sedatives are essential for relieving anxiety and pain in mechanically ventilated patients. The guidelines for the management of pain, agitation and delirium in adult ICU patients in the United States suggest analgesic priority sedation strategies, reaffirm the importance of analgesic treatment in the ICU and recommend intravenous opioids as a first line option for the treatment of non-neurotic pain in critically ill patients ${ }^{[7-10]}$. As a new member of the fentanyl family, remifentanil has a short halflife, belongs to a powerful opioid analgesic and has many advantages such as fast onset, short duration of action, rapid recovery, no accumulative effect and easy control of anesthesia depth ${ }^{[11,12]}$.

In this study, the analgesic and sedative effects of remifentanil and sufentanil combined with dexmedetomidine on patients with mechanical ventilation were discussed. Data analysis showed that both groups achieved good analgesic and sedative effects, but group $\mathrm{R}$ had better sedative effect, so the sedative effect of group $\mathrm{R}$ was better than group S. The physiological indexes of HR, MAP and RR in the two groups were significantly reduced after administration and the indexes of MAP and RR in the R group were better than those in the $\mathrm{S}$ group. The satisfactory analgesic and sedative time (min), mechanical ventilation time (h) and ICU hospitalization time (h) of group $\mathrm{R}$ were also better than group $\mathrm{S}$. Adverse reactions occurred in both groups.

To sum up in the ICU mechanical ventilation in patients with fentanyl analgesia based sedative treatment, can quickly achieve the purpose of soothing calm, improve the patient's physiological indexes, shorter reach satisfactory analgesia in patients with calm, mechanical ventilation time and ICU length of hospital stay, for the application of mechanical ventilation in patients with analgesic calm strategy, provide certain research value.

\section{Conflicts of interest:}

The authors declared no conflict of interest. 


\section{REFERENCES}

1. Ely EW, Shintani A, Truman B, Speroff T, Gordon SM, Harrell Jr FE, et al. Delirium as a predictor of mortality in mechanically ventilated patients in the intensive care unit. JAMA 2004;291(14):1753-62.

2. Cai XF, Zhang FR, Zhang L, Sun JM, Li WB. Efficacy of analgesic and sedative treatments in children with mechanical ventilation in the pediatric intensive care unit. Chin J Contemp Pediatr 2017;19(11):1138-44.

3. Marik PE, Cavallazzi R, Vasu T, Hirani A. Dynamic changes in arterial waveform derived variables and fluid responsiveness in mechanically ventilated patients: a systematic review of the literature. Crit Care Med 2009;37(9):2642-7.

4. Liu SX, Shi YF, Chen XB, Wang YL, Liu KX. Application of Remifentanil in Patients with Mechanical Ventilation in ICU. Chinese J Mod Med 2016;18(11):15-9.

5. Patel SB, Kress JP. Sedation and analgesia in the mechanically ventilated patient. Am J Respir Crit Care Med 2012;185(5):48697.

6. Lellouche F, Dionne S, Simard S, Bussieres J, Dagenais F. High tidal volumes in mechanically ventilated patients increase organ dysfunction after cardiac surgery. Anesthesiology 2012;116(5):1072-82.

7. Cook DJ, Pearl RG, Cook RJ, Guyatt GH. Incidence of clinically important bleeding in mechanically ventilated patients. J Intensive Care Med 1991;6(4):167-74.
8. Zhu XW, Peng YF, Wang Y. Comparison of sedative and analgesic effects of dexmedetomidine and midazolam combined with remifentanil on mechanical ventilation of trauma patients. China Pharm 2015;24(24):108-9.

9. Dahaba AA, Grabner T, Rehak PH, List WF, Metzler H. Remifentanil versus morphine analgesia and sedation for mechanically ventilated critically ill patients: a randomized double blind study. Anesthesiology 2004;101(3):640-6.

10. Volmanen P, Akural EI, Raudaskoski T, Alahuhta S. Remifentanil in obstetric analgesia: a dose-finding study. Anesth Analg 2002;94(4):913-7.

11. Thurlow JA, Laxton CH, Dick A, Waterhouse P, Sherman L, Goodman NW. Remifentanil by patient-controlled analgesia compared with intramuscular meperidine for pain relief in labour. Br J Anaesth 2002;88(3):374-8.

12. Vincent JL, Shehabi Y, Walsh TS, Pandharipande PP, Ball JA, Spronk P, et al. Comfort and patient-centred care without excessive sedation: the eCASH concept. Intensive Care Med 2016;42(6):962-71.

This is an open access article distributed under the terms of the Creative Commons Attribution-NonCommercial-ShareAlike 3.0 License, which allows others to remix, tweak, and build upon the work non-commercially, as long as the author is credited and the new creations are licensed under the identical terms

This article was originally published in a special issue,
"Therapeutic Perspectives in Biomedical Research and Pharma-
ceutical Sciences and their Nursing Methods"
Indian J Pharm Sci 2021:83(4)Spl issue "178-183"

